\title{
Prostate biopsy: a survey of practice among Nigerian urologists
}

\author{
Taofiq O. Mohammed ${ }^{1 *}$ (D), Abdulwahab A. Ajape ${ }^{2}$, Suleiman A. Kuranga ${ }^{2}$, Hamid B. Olanipekun ${ }^{1}$ and \\ Tolulope T. Ogunfowora'
}

\begin{abstract}
Background: Prostate biopsy is a commonly performed outpatient procedure in urology. It is a rapidly changing field with wide variation in practice pattern. The aim of this study is to document the current practice of prostate biopsy among Nigerian urologists.

Methods: A prospectively designed, self-administered, 16-item survey questionnaire was distributed among urologists and trainees at the 24th Annual General Meeting and Scientific Conference of the Nigerian Association of Urological Surgeons (NAUS). The survey covers various aspect of prostate biopsy including indications for biopsy, prophylactic antibiotic regimen use, methods of bowel preparation, number of biopsy cores taken, complications among others.
\end{abstract}

Results: Fifty-one completed questionnaires were returned, out of 76 distributed, giving a response rate of $67 \%$. Majority of the respondents were Consultant urologist 47 (92\%), most of them practice in the public health system 46 (90.2\%), and performed more than 5 prostate needle biopsy per month 37 (72.5\%). All respondents administer prophylactic antibiotics prior to biopsy, with intravenous Gentamycin being the most commonly administered prophylactics 14 (27.5\%), only a few perform bowel preparations prior to biopsy 8 (15.7\%) with Dulcolax suppository being the most commonly employed agents 5 (63\%). Most of the biopsy were done under transrectal ultrasound guidance 29 (56.9\%). None of the respondents performed MRl-guided transrectal biopsy. Most respondents take 8-12 core biopsy 20 (39.2\%), using 18G trucut biopsy needle 31 (60.8\%), with the patient in left lateral decubitus position $26(51 \%)$, under $2 \%$ intrarectal xylocaine instillation 28 (54.9\%). The commonest complication after the procedure was bleeding per rectum 20 (39.2\%), followed by haematuria 9 (17.6\%), and infection 8 (15.7\%).

Conclusion: There is universal use of prophylactic antibiotic prior to biopsy. However, bowel preparation prior to biopsy is not common among Nigerian urologist, and MRI-guided biopsy is very rarely done for prostate biopsy. There is need for a prostate biopsy guideline among Nigerian urologists to ensure uniformity of practice, and enhance standardized service delivery.

Keywords: Transrectal prostate needle biopsy, Targeted antibiotic prophylaxis, Bowel preparation

\section{Background}

Prostate biopsy is one of the most commonly performed out-patient procedures in urology [1]. It's a rapidly changing field that has evolved over the years from aspirating

\footnotetext{
*Correspondence: mohdtaofiqo@gmail.com

${ }^{1}$ Division of Urology, Department of Surgery, University of Ilorin Teaching Hospital, llorin, Nigeria

Full list of author information is available at the end of the article
}

cells from the prostate for cytologic analysis to imageguided biopsy for histopathologic analysis [2, 3]. Transrectal ultrasound-guided systematic prostate biopsy is the current gold standard modality for obtaining histologic diagnosis for prostate cancer $[4,5]$. However, new evidences are available showing that MRI-guided combined targeted and systematic biopsy may be the emerging, new gold standard [6]. Many urology units/centres 
in Sub-Sahara Africa have yet to fully embrace TRUSguided prostate biopsy for lack of the facility for such undertaking; many units still rely on the abandoned practice of digitally guided needle biopsy.

A variation in the practice in not unexpected in the developing nations of the world, more especially in the Sub-Sahara Africa due to reasons that ranges from nonavailability of necessary equipment to high poverty level that cannot sustain the option of "out-of-pocket" healthcare that is being practiced in most of these developing nations [7].

The present study aimed at documenting the prostate biopsy practice pattern among Nigerian urologists with a view to forming a basis for standardization.

\section{Methods}

A prospectively designed, self-administered, 16-item survey questionnaire was distributed among urologists and trainees at the 24th Annual Scientific Conference and Annual General Meeting of the Nigerian Association of Urological Surgeons (NAUS), held at Usman Danfodiyo University (UDUTH), Sokoto, Nigeria, between the 27th to 30th November, 2018. Permission to administer the questionnaire was sought from and given by NAUS executives. Apart from Demographic information of the respondents, the survey covers various aspects of prostate biopsy including indications for biopsy, prophylactic antibiotic regimen use, methods of bowel preparation, number of biopsy cores taken, use of image guidance, complications among others. The data collected were entered into IBM SPSS for Windows (IBM Corp, Armonk, New York, United States of America) version 22 for analysis.

\section{Results}

A total of seventy-six questionnaires were distributed among participants. Fifty-one completed questionnaires were returned, giving a response rate of $67 \%$. Majority of the respondents were Consultant urologist 47 (92\%). Most of them practice in the public health system 46 $(90.2 \%)$ and perform more than five (5) prostate needle biopsy per month 37 (72.5\%). Other demographic information is as shown in Table 1.

All respondents administer prophylactic antibiotics prior to biopsy. Intravenous gentamycin is the most frequently administered prophylactics antibiotic 14 (27.5\%); this is closely followed by ciprofloxacin and ceftriaxone $10(19.6 \%)$ and 9 (17.7\%), respectively (Fig. 1). Other respondents used a combination of these antibiotics for varying duration which ranges from one to five days post biopsy. Only a few of the respondents 2 (3.9\%) administer culture guided antibiotic prophylaxis. The respondents
Table 1 Demographic characteristics of respondents

\begin{tabular}{lc}
\hline Variables & Frequency (\%) \\
\hline Status of respondents & $47(92)$ \\
Consultants & $4(8 \%)$ \\
Trainees & \\
Duration of practice (years) & $24(47)$ \\
$<5$ & $13(25.5)$ \\
$5-10$ & $14(27.5)$ \\
$>10$ & \\
Practice setting & $46(90.2)$ \\
Public & $5(9.8)$ \\
Private & \\
Practice location in Nigeria & $14(27.5)$ \\
South west & $3(5.9)$ \\
South east & $2(3.9)$ \\
South south & $10(19.6)$ \\
North west & $7(13.7)$ \\
North east & $15(29.4)$ \\
North central &
\end{tabular}

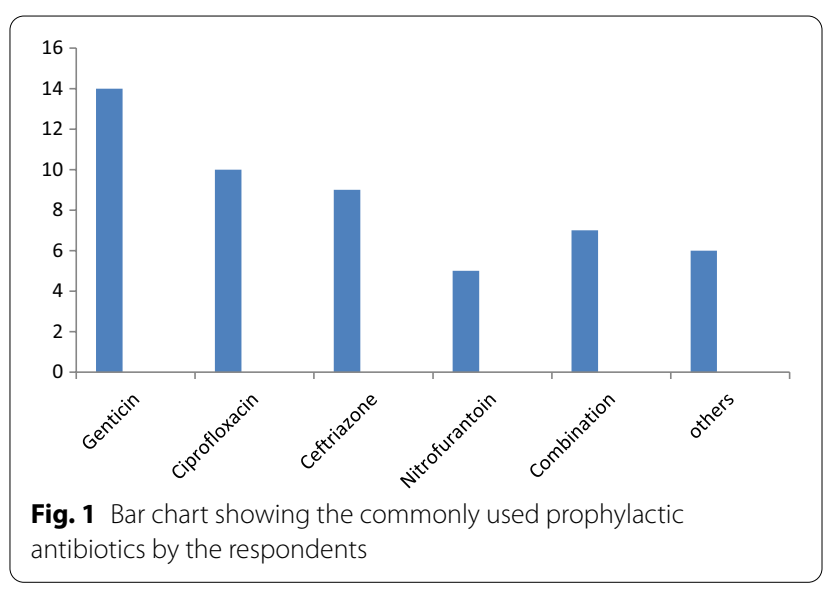

predominantly practice empirical antibiotics prophylaxis (Table 2).

A few of the respondent perform bowel preparations prior to biopsy $8(15.7 \%)$ using majorly Dulcolax suppository. More than half of the respondent performs transrectal ultrasound-guided systematic prostate biopsy 29 (56.9\%); others perform digitally guided biopsy 22 (43.1\%). None of the respondents performs MRI-guided targeted or systematic prostate biopsy, and none performs transperineal biopsy (Figs. 2 and 3).

Most respondents take an average of eight to 12 cores biopsy 20 (39.2\%), using $18 \mathrm{G}$ semi-automatic trucut biopsy needle $31(60.8 \%)$, with the patient in left lateral decubitus position 26 (51\%), under $2 \%$ intrarectal xylocaine instillation 28 (54.9\%) (Table 2 and Figs. 3, 4). The 
Table 2 Showing some practice pattern among respondents

\begin{tabular}{lc}
\hline Number of biopsy cores & $\begin{array}{l}\text { Number of } \\
\text { respondents } \\
\text { (\%) }\end{array}$ \\
\hline 6 & $17(33.3)$ \\
$8-12$ & $20(39.2)$ \\
$>12$ & $14(27.5)$ \\
Trucut biopsy needle size (G) & \\
$16 G$ & $20(39.2)$ \\
$18 G$ & $31(60.8)$ \\
Duration of antibiotics use (days) & \\
$1-2$ & $7(13.7)$ \\
$3-5$ & $28(54.9)$ \\
$>5$ & $16(31.4)$ \\
Rectal culture directed antibiotic prophylaxis & \\
Yes & $3(5.9)$ \\
No & $48(94.1)$ \\
Positioning & \\
Left lateral decubitus & $26(50.9)$ \\
Lithotomy & $12(23.5)$ \\
Right lateral decubitus & $6(11.8)$ \\
Knee Elbow position & $7(13.7)$ \\
\hline
\end{tabular}

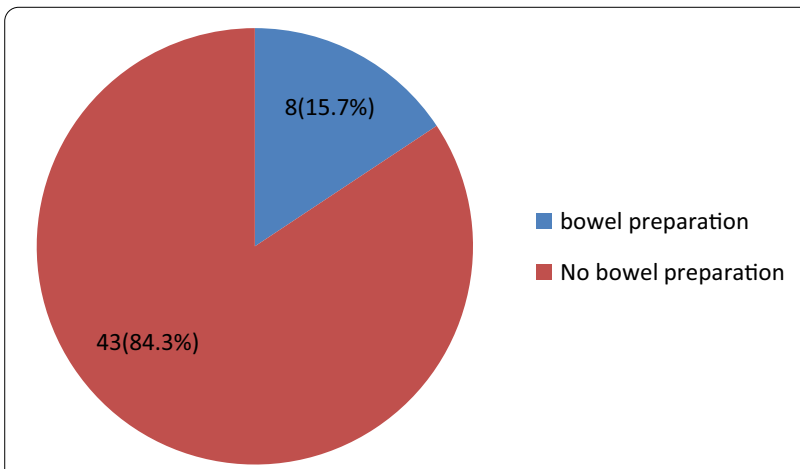

Fig. 2 Pie Chart showing the use or otherwise of bowel preparation prior to prostate biopsy

commonest complication after the procedure was bleeding per rectum 20 (39.2\%), followed by haematuria 9 (17.6\%), and infection 8 (15.7\%), Fig. 5.

\section{Discussion}

The result from the present study of practice survey has demonstrated that prophylactic antibiotic use prior to prostate biopsy is universal among respondents. All of the respondents administer an antibiotic prior to the procedure; this is in keeping with standard global best practice. It has been shown in prospective randomized control trials that prophylactic antibiotics use, when
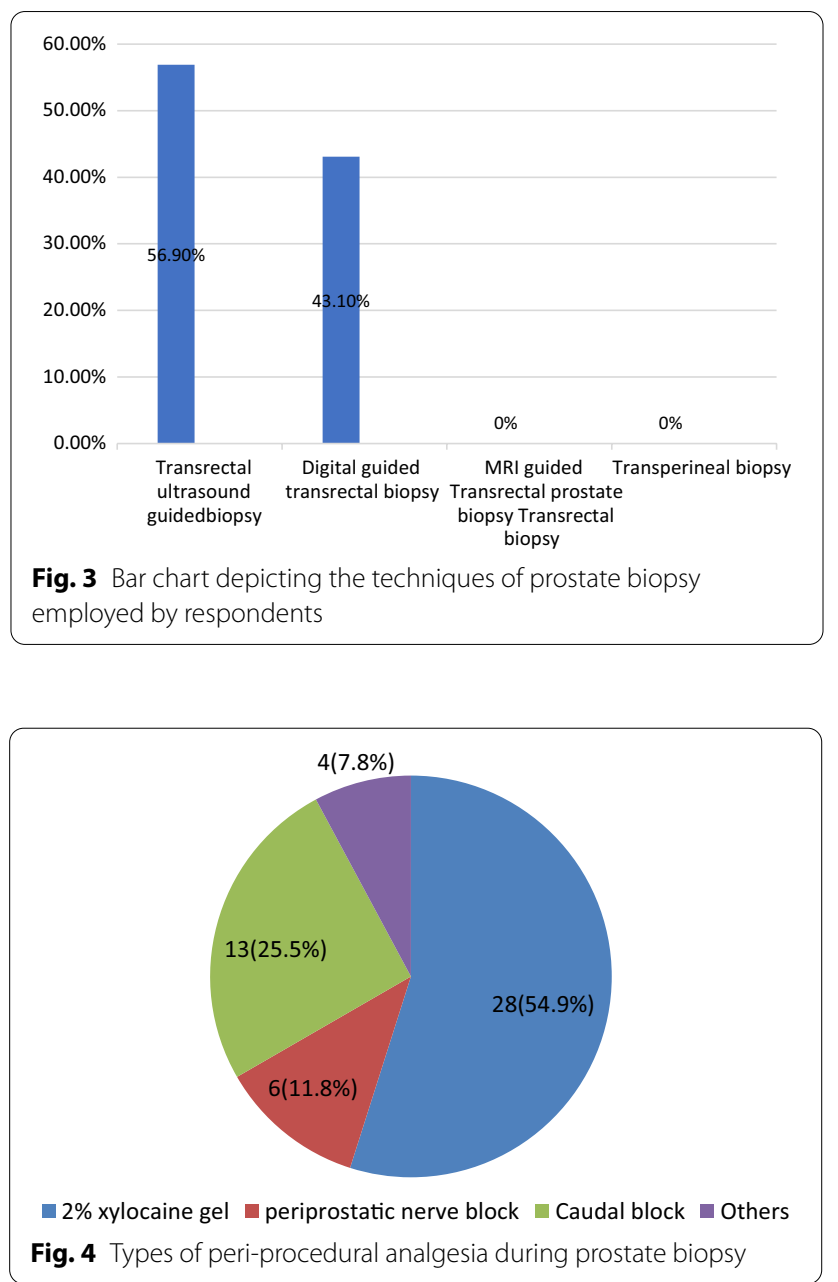

compared to placebo, is effective in reducing infectious complications after prostate biopsy [8, 9]. However, the choice of antibiotics and the duration of antibiotic use vary, with most respondents using a three to five days course of antibiotics. This variation in choice, and duration of antibiotic use was also reported by other researchers [10-13]. Intravenous gentamycin is the most commonly administered prophylactic antibiotics in the present study. This is in contrast to other studies which reported fluoroquinolones as the most commonly administered antibiotics for prophylaxis prior to prostate biopsy $[10,11,14]$. The choice of gentamycin in this study may not be unrelated to the growing global concern for fluoroquinolone resistance and wide spread misuse in the poultry and agricultural sectors in this environment [14-16]. Empirical prophylactic antibiotic administration was practiced predominantly in this survey, admittedly by $94.1 \%$ of the respondents. In contrast however, culture-guided antibiotic prophylaxis, using rectal swab microscopy, culture and sensitivity, is 
increasingly becoming more popular as a way to stem the tide of rising post-biopsy infectious complications, particularly in patients with risk factors for faecal carriage of fluoroquinolone resistant organisms [17-19]. There is currently a dearth of conclusive evidence to recommend routine use of culture guided antibiotics prophylaxis in clinical practice; thus the decision to use it is left at the discretion of the managing clinician [20].

Bowel preparation is not routinely being practice by Nigerian urologists; a total of eight of the respondents in this survey, representing $15.7 \%$, does bowel preparation prior to prostate biopsy. Rectal preparation prior to biopsy is done based on the proposition that it will reduce bacterial load in the rectal vault and, hence, decreases incidence of post-biopsy infectious complications [21]. Rectal cleansing with enemas, suppositories, or povidone iodine lavage has not been found to be of significant benefits in patients who has received antibiotic prophylaxis [22]. However, the EAU guidelines recommend the use of rectal cleansing prior to biopsy based on a meta-analysis of six trials that showed that combining rectal cleansing with antibiotics resulted in lower incidence of infectious complications compared with antibiotics alone [20].

Transrectal ultrasound-guided prostate biopsy with extended cores is the commonest method of obtaining prostatic needle biopsy in this survey, but digitally guided transrectal prostate needle biopsy is also fairly common. This is in contrast to what Jeje et al. [10], in a similar survey conducted in the year 2014 but published in the year 2020 reported, in which digital-guided transrectal prostatic needle biopsy was the commonest method of obtaining prostatic needle biopsy. This represents a commendable shift towards the adoption of transrectal ultrasound-guided biopsy among Nigerian urologist. Despite increasing role of multi-parametric MRI and its recommendation by EAU in selecting patients for and

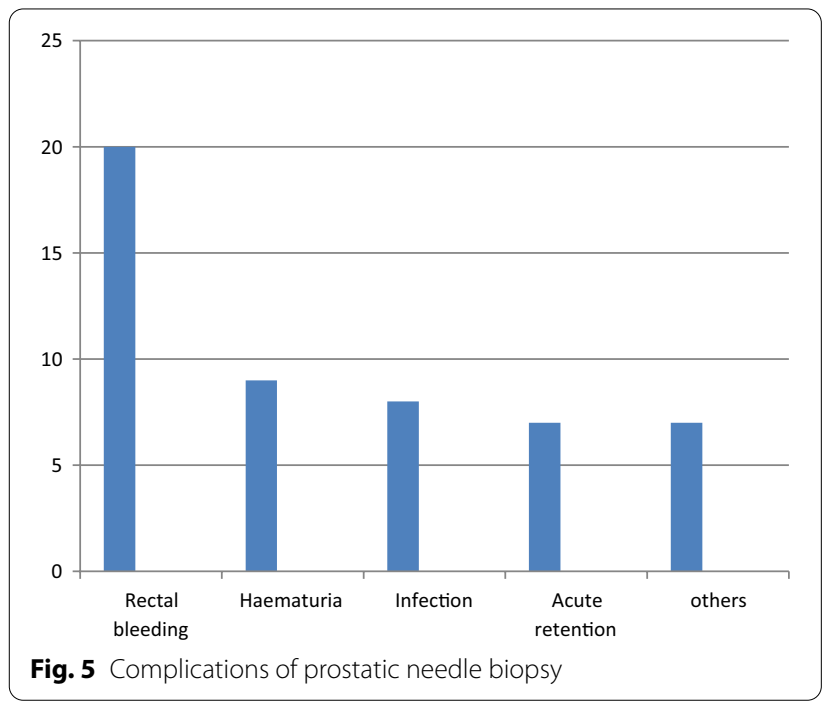

guiding prostatic needle biopsy both in biopsy naïve and in patients undergoing repeat biopsy after previous negative prostatic biopsy, MRI-guided prostate biopsy is not practiced among respondents in this survey [20]. This may be due to the high cost of MRI, its non-availability and limited expertise in the technique.

The respondents in this survey are fairly well distributed across all geo-political zones of the country, although they represent a small proportion of the number of registered practicing urologists and trainees within the country. Nonetheless, this survey provides an insight into the current practice pattern among Nigerian Urologist.

\section{Conclusion}

In conclusion, there is some variations in practice pattern among Nigerian urologists as regards prostate needle biopsy. Transrectal ultrasound-guided biopsy is the most common techniques employed, digitally guided biopsy is still fairly commonly practiced while MRI-guided biopsy is rarely practiced among respondents in this study. Prophylactic antibiotic use prior to biopsy is universal, and Gentamycin is the most commonly used prophylactic antibiotics. There is a need to standardize prostate biopsy practice pattern so as to enhance uniformity of care to patients based on good evidence.

\section{Abbreviations}

EAU: European Association of Urologist; MRI: Magnetic Resonance Imaging; NAUS: Nigerian Association of Urological Surgeons; TRUS: Transrectal Ultrasound; UDUTH: Usman Danfodiyo University Teaching Hospital.

\section{Acknowledgements}

We are grateful to the executives and members of the Nigerian Association of Urological Surgeons for approving this study and for participating respectively.

\section{Authors' contributions}

AAA conceptualized the idea for this paper. AAA, TOM and $\mathrm{HBO}$ designed the survey questionnaire. TOM, HBO and TTO collected the data, supervised by AAA and SAK. TOM analysed the data. TOM wrote the first draft of this manuscript. AAA reviewed the first draft. All authors read and approved the final manuscript.

Funding

This work was not supported by any external source of funding.

Availability of data and materials

Available upon reasonable request from the corresponding author.

\section{Declarations}

Ethics approval and consent to participate

Approval to administer, the questionnaire among the delegates at the conference was obtained from the executives of the Nigerian Association of Urological Surgeons (NAUS).

Consent for publication

Not applicable. 


\section{Competing interests}

All authors declare no conflicts of interest.

\section{Author details}

${ }^{1}$ Division of Urology, Department of Surgery, University of Ilorin Teaching Hospital, llorin, Nigeria. ${ }^{2}$ Division of Urology, Department of Surgery, University of Ilorin, University of Ilorin Teaching Hospital, Ilorin, Nigeria.

Received: 12 August 2021 Accepted: 8 September 2021

Published online: 23 September 2021

\section{References}

1. Loeb S, Vellekoop A, Ahmed HU, Catto J, Emberton M, Nam R et al (2013) Systematic review of complications of prostate biopsy. Eur Urol 64(6):876-892

2. Ferguson RS (1930) Prostatic neoplasms: their diagnosis by needle puncture and aspiration. Am J Surg 9:507-511

3. Astraldi A (1937) Diagnosis of cancer of the prostate: biopsy by rectal route. Urol Cutan Rev 41:421-424

4. Hodge KK, McNeal JE, Terris MK, Stamey TA (1989) Random systematic versus directed ultrasound guided transrectal core biopsies of the prostate. J Urol 142:71-74

5. Epstein Jl, Walsh PC, Sauvageot J, Carter HB (1997) Use of repeat sextant and transition zone biopsies for assessing extent of prostate cancer. J Uro 158:1886-1890

6. Kasivisvanathan V, Rannikko AS, Borghi M, Panebianco V, Mynderse LA, Vaarala MH et al (2018) MRI-targeted or standard biopsy for prostatecancer diagnosis. N Engl J Med 378(19):1767-1777

7. Udeh El, Onwujekwe OE, Adewole DA, Onoka CA (2016) Exploring the threshold premium for viable community based health insurance schemes in Nigeria. BMC Res Notes 9:383-395

8. Aron M, Rajeev TP, Gupta NP (2000) Antimicrobial prophylaxis for transrectal needle biopsy of the prostate:a randomized control study. BJU Int 85:682-688

9. Schaeffer AJ, Wolf JS, Beneth CJ, Dmochowski RR, Hollenbeck BK, Pearle MS et al (2008) Best practice policy statement on urologic surgery antimicrobial prophylaxis. J urol 179:1379-1390

10. Jeje EA, Alabi TO, Ojewola RW, Ogunjimi MA (2020) Survey of prostate biopsy practices among urologists in Nigeria. Niger Postgrad Med J 27(4):377-383
11. Davis P, Paul E, Grummet J (2015) Current practice of prostate biopsy in Australia and New Zealand: a survey. Urol Ann 7(3):315-319

12. Tops SCM, Koldewijn EL, Somford DM, Huis AMP, Kolwijck E, Wertheim HFL et al (2020) Prostate biopsy techniques and pre-biopsy prophylactic measures: variation in current practice patterns in the Netherlands. BMC Urol 20(1):24-33

13. Fink KG, Schmid HP, Paras L, Schmeller NT (2007) Prostate biopsy in Central Europe: results of a survey of indication, patient preparation and biopsy technique. Urol Int 79(1):60-66

14. Loeb S, Carter HB, Berndt SI, Ricker W, Schaeffer EM (2011) complications after prostate biopsy: data from SEER-medicare. J Urol 186:1830-1834

15. Adelowo OO, Fagade OE, Obasola E, Agerso Y (2014) Antibiotic resistance and resistance genes in Escherichia coli from poultry farms, southwest Nigeria. J Infect Dev Ctries 8(9):1103-1112

16. Egwuenu A, Obasanya J, Okeke I, Aboderin O, Olayinka A, Kwange D, Ogunniyi A, Mbadiwe E, Omoniyei L, Omotayo H, Niyang M (2017) Antimicrobial use and resistance in Nigeria: situation analysis and recommendations

17. Lee S-J (2015) Infection after transrectal ultrasound-guided prostate biopsy. Korean J Urol 56(5):346-350

18. Cussans A, Somani BK, Basarab A, Dudderidge TJ (2016) The role of targeted prophylactic antimicrobial therapy before transrectal ultrasonography-guided prostate biopsy in reducing infection rates: a systematic review. BJU Int 117(5):725-731

19. Taylor AK, Zembower TR, Nadler RB, Scheetz MH, Cashy JP, Bowen D et al (2012) Targeted antimicrobial prophylaxis using rectal swab cultures in men undergoing transrectal ultrasound guided prostate biopsy is associated with reduced incidence of postoperative infectious complications and cost of care. J Urol 187(4):1275-1279

20. Bonkat $G$, Pickard R, Bartoletti R, Bruyère $F$, Geerlings $S$, Wagenlehner $F$, Wullt B, Pradere B, Veeratterapillay R (2018) Urological infections. European Association of Urology, Arnhem

21. Davis M, Sofer M, Kim SS, Soloway MS (2002) The procedure of transrectal ultrasound guided biopsy of the prostate: a survey of patient preparation and biopsy technique. J Urol 167:566-570

22. Zaytoun O, Anil T, Mousa A, Jianbo L, Jones J (2011) Morbidity of prostate biopsy after simplified versus complex preparation protocols:assessment of risk factors. Urology 77(4):910-914

\section{Publisher's note}

Springer Nature remains neutral with regard to jurisdictional claims in published maps and institutional affiliations.

\section{Submit your manuscript to a SpringerOpen ${ }^{\circ}$ journal and benefit from:}

- Convenient online submission

- Rigorous peer review

- Open access: articles freely available online

- High visibility within the field

Retaining the copyright to your article

Submit your next manuscript at springeropen.com 